\title{
A cena da crítica contemporânea: artes expandidas \& sociedades contraídas
}

\author{
LUIZ FERNANDO RAMOS
}

The text departs from the perspective of an expanded scene in which the several artistic fields are mixed in new forms, hybrid and transgenic. It discusses the tension between the supposed essence and specificity of each one of the arts (teknês) and this expansion diluting frontiers. It proposes then the notion of a performative mimesis, differentiated from the dramatic mimesis, projecting all these distinct arts in a common field in which different means get mixed. Facing those premises, we reflect on the question of the artistic critic in the contemporaneity, retaking the David Hume's essay on the Pattern of Taste in contrast with the Immanuel Kant's Critic of Judgment and discussing the hegemony of the Deleuzian philosophy in the present critic essays on art.

THEATRE CRITICISM / PUBLIC SPHERE / MIMESIS / PERFORMANCE / ART CRITICISM

Pretende-se aqui apresentar uma reflexão bem pessoal sobre questões que envolvem, ou que implicam, a crítica de artes do espetáculo hoje, bem como especular em torno de suas reverberações na esfera pública. O título escolhido adveio da disposição de discutir o paradoxal contraste entre o caráter expansivo das artes, pelo menos como eu as reconheço em franco processo de fusão, ainda que também friccionadas, e o modo construtivo como as nações de uma maneira geral e as sociedades civis, em cada uma delas, vêm agindo no sentido de manutenção de seus territórios, confortos e hábitos. O que apresento em seguida é uma tentativa, ou exercício, de responder aquela disposição, mas é também uma sincera devolutiva, fundada nas experiências e práticas com o fazer, o pensar e o repropor processos teatrais criativos, fossem os meus próprios ou o de outros artistas, e com o escrever relatos, de pesquisas de ações e cenas, ou críticas de espetáculos e performances. Neste escrever, a partir da impressão sensível das obras que se apresentaram e do seu processamento na imaginação, ocorreu-me sempre estar havendo 
uma interlocução com os leitores imediatos e contemporâneos à crítica e com os artistas criadores daquelas obras observadas, mas nunca deixei de acalentar que poderia estar dialogando também com leitores futuros, que em um outro tempo colheriam minhas palavras como testemunhos de uma época.

Passo agora a interseccionar as questões propostas pelos que pensaram esse dossiê com alguns pontos que vim colecionando na reflexão sobre a crítica de arte e sobre as artes contemporâneas, principalmente nas suas vertentes performativas, cujo escopo crítico abarca as artes do espetáculo. Em relação ao «caráter interdisciplinar das práticas artísticas», pode partir-se da perspectiva de uma cena expandida, em que os campos reconhecidos - pintura, música, escultura, vídeo, cinema, dança, teatro e performance - aparecem mesclados, fundidos e hibridados em novas formas, que eu diria transgênicas. Cabe também acolher-se o paradoxo de que, simultaneamente, cada um desses meios e modos representacionais tende a fechar-se em copas diante de uma especificidade essencial, da qual nunca poderiam eximir-se ou que, em última instância, não podem mesmo abandonar.

A planaridade para a pintura, a tridimensionalidade para a escultura, a musicalidade para a música, as imagens em movimento para o cinema e o vídeo, e a convivência temporal, simultânea e reativa, de observadores diante do apresentado para o teatro e a performance.

Cada um desses aspectos singulares a essas «artes» (teknês) resiste por dentro da linguagem de uma cena performativa expandida, que os arregimenta e processa de diversas maneiras e com propósitos múltiplos. Sem contar que no plano da indústria cultural, do mercado de arte, do teatro e da dança comerciais e de suas instituições mantenedoras, prevalece mesmo um compromisso de cada uma dessas artes com a sua identidade padrão, oficialmente chancelada e que se reproduz e distribui torrencialmente, seja nos clichês que a Internet proporciona e que se adensam em vertiginosa redundância nas ditas redes sociais, seja na fruição massiva de museus espetaculares e de outros eventos monumentais.

De fato, verdadeiramente, essa arte expandida só existiria no âmbito de processos de invenção, ou de artistas que, de qualquer uma de suas especificidades, conseguissem transitar livremente arrebanhando os recursos necessários de cada um desses meios para propor sínteses genuínas, em que a própria ideia de obra de arte reapareceria transcendida das categorias clássicas, e sendo reproposta nessa amplitude vaga a que as remetemos quando falamos de uma cena expandida. 
A palavra cena, no entanto, favorece pensar que predominem nessas formas expressivas e seja característico de sua historicidade o aspecto performativo, de desempenho ativo em tempo real na produção da obra, e espetacular, direcionado a espectadores distanciados, que fruem as obras simultaneamente à sua apresentação, em um tempo limitado e em circunstâncias não exatamente repetíveis, sendo eles próprios performers. Nesse sentido, talvez, interessasse retomar a velha noção de mimesis dos Gregos, até por em sua raiz platônica, em chave negativa, caracterizar a apresentação performativa e dramática, e em Aristóteles, já positivada como produtiva, além do foco na narrativa espetacular, abraçar todas as artes sob um mesmo teto, diferindo as mesmas pelos meios e modos distintos de apresentação. Halliwell demonstrou, em sua bem sustentada história da mimesis, como essa noção complexa pode referir tanto fenômenos de espelhamento do mundo como de criação de novos e originais mundos, antes inexistentes (Halliwell, 2002). Como essa apontada cena expandida opera necessariamente no campo da invenção, ou seja, na ruptura com os modelos e as normas da convenção de cada uma das ditas «artes» por si, e ainda que tenham em comum o caráter performativo e espetacular, distanciam-se no geral das narrativas dramáticas estritas, o que quer dizer que não «funcionam» como mecanismos de reconhecimento, ou pelo menos se afastam do jogo de encaixes com referentes seguros. Para caracterizar esses fenômenos em específico, tenho utilizado a noção de mimesis performativa, principalmente para analiticamente os diferenciar da mimesis dramática e permitir projetar as artes na perspectiva de um campo comum, onde se hibridam vários meios (Ramos, 2015). É claro que assim nos distanciamos do dito teatro, com sua forma específica, seus cânones, normas e técnicas, e ampliamos o fenômeno performativo à dimensão de uma arte aberta a todos os meios. Essa arte-arte, ou esse teatro-arte, são mais raros do que parece. Despontam como experimentações efêmeras e isoladas, ainda que nos últimos vinte anos se tenham consolidado, sobretudo na Europa, numa quantidade e constância que já permite pensá-los como uma tradição pós-moderna. Mas essa pertença ao mundo da arte como fenômenos estéticos de ponta, propulsionados pelo apoio institucional dos grandes museus e festivais, só confirma a convivência tensa com modelos resistentes de arte, nutridos nos conservatórios e defensores da especificidade de cada um dos meios produtivos, de cada uma das teknês.

Na situação contemporânea, pois, o esgotamento dos cânones, já não prodigalizados no ensino das artes e quase inoperantes nos exercícios 
críticos, ocorre simultâneo à manutenção de padrões estéticos pelo simples hábito de seu uso generalizado e pela tendência à mediania que se espalha pelas «escolas» e pelos departamentos. A crítica de arte em geral, e a de teatro em particular, reflete de algum modo essa oposição, pressionada pelos grandes jornais a atender consumidores numa crítica de gosto, e desafiada por artistas inventivos a lançar-se numa produção ensaística mais densa.

Ao mesmo tempo, retomando o paradoxo já indicado em novos termos, é possível apontar a emergência da invenção e da radicalidade em processos construtivos, em que cada uma das artes se supera e repropõe exatamente por um máximo de restrição às suas especificidades, por um ir no limite ao encontro de suas essências. No caso do teatro, por exemplo, essa contração pode levar a cena ao esvaziamento completo de recursos externos ao do corpo a corpo de atores e público em tempo real, postos a nu sem ficção ou faz de conta que sustente seu diálogo presencial, mas ainda presentes e simultâneos. De algum modo, a cena performativa contemporânea, distante do drama, mas também proposta além da ojeriza à representação da performance arte, adensa esse osso essencial do ato performativo e sugere novos modos narrativos, mais próximos da abstração plástica e pictórica e da fluidez da música. Curiosamente, essa tendência confirma as profecias de Gordon Craig, ele próprio um essencialista em busca da especificidade do cênico, sobre uma nova arte, a da arquitetura musicalizada e em movimento, que se já não contava em sua forma mais radical com atores mascarados de personagens, ainda precisava de operadores humanos neutros e focados, agentes mobilizadores de uma estrutura plástica e visual (Craig, 2017). Nestes desempenhos físicos e concretos ali intuídos, já se antecipava essa amplitude do que hoje abarca espetáculos, performances e instalações interativas, que acontecem tanto em teatros como em museus, nas ruas como em sítios específicos (Ramos, 2017).

Em relação ao papel central atribuído ao espectador, emancipado do cabresto dos emissores e valorizado como agente produtor no convívio com a obra em processo, é interessante que a ideia de jogo performativo o inclua necessariamente em condições de igualdade na dimensão criadora. Quer dizer, mesmo quando apenas contempla, a participação do observador é ativa, no sentido de não ser destinatária de um sentido ou mensagem pré-determinada, mas produtora de uma solução possível diante da aparente indefinição de princípio do jogo jogado.

Se falássemos estritamente da recepção musical ou pictórica e plástica, esse jogo indefinido e aberto não traria nenhuma novidade. Quando ele 
ocorre na cena, e mais especificamente no campo do drama, a questão se torna mais complexa, por estar-se em um território eminentemente semântico em que, mesmo quando submetido a operações formais de desfazimento de tramas e adensamento das opacidades, ainda se guarda a nostalgia de um sentido final, de um desfecho apaziguador. Mesmo assim, por qualquer dos meios em que se dê a ação performativa e cênica, nessa perspectiva tipicamente contemporânea, os espetáculos, performances ou instalações interativas serão sempre fazeres de conta temporários em que o espectador, mais do que destinatário, torna-se produtor, ou poietés, dessas obras, bem como agente de sua recepção crítica. Mas no que difere então esse faz de conta enigmático, sem descoberta do tesouro, do que se dá na fruição dramática mais habitual, a melodramática, com seus dispositivos de mil encaixes perfeitos? Talvez apenas a inquietação residual, que permanece acesa no espectador da obra aberta ou, quem sabe, bem mais que isso, a experiência lúdica com a graça da brincadeira e o sentimento de pertencimento no jogo libertador da estética.

É diante dessas premissas que, acredito, deve-se pensar a questão da crítica contemporaneamente e que chego às questões específicas propostas por este Dossiê Temático.

Se os discursos críticos inevitavelmente negociam com as condições sociopolíticas e culturais em que habitam, porque são sempre históricos, além dos apontados caráter indisciplinar das artes hoje e papel preponderante do espectador em sua consumação, haveria de se considerar os novos meios tecnológicos e os modos de circulação global dos discursos.

Imediatamente me ocorre uma situação, possível na atualidade, em que um espetáculo não estará mais permeável a uma única crítica presencial, mas, gravado, se submeteria, transposto para a rede e suas infinitesimais recepções, seja a novas leituras do mesmo crítico, seja às leituras potenciais de terceiros que só o assistirão nas versões fílmicas. É, sem dúvida, uma crítica estendida e expandida do território do jogo e da poiesis presencial, mas que também se arrisca, na sua fragilidade reprodutível, a dissipar-se e dissolver-se na sopa de sensos comuns e opiniões, servida permanentemente pelo banquete internético. Quando esta crítica, esta leitura especializada no plano aberto e múltiplo das redes sociais, será potente e jogará de fato com criadores e público, ampliando sentidos e não compactuando com a mediocridade de expectativas, ou com o apequenar dos vastos horizontes? Em que lugar a crítica pode fulgurar e ir além dos preconceitos corrosivos, dos cânones mortos e das 
prisões mentais? Como poderá ela fazer-se relevante enquanto obra à altura daquelas que examina e explora? Muitas serão as possíveis respostas a essas perguntas, e enunciá-las e contrapô-las, numa dialética coletiva que faça emergir não consensos vazios, mas contraditórios plenos é uma expectativa almejável para esse número de Sinais de Cena.

Para encaminhar a discussão, decidi partir de um clássico da crítica de arte pós-renascentista, até pelo seu caráter seminal, de rica semente da reflexão kantiana e moderna sobre a estética. Trata-se do ensaio do filósofo escocês David Hume sobre o padrão de gosto como um valor a ser defendido, e a presunção, implícita a esta defesa, de que a melhor forma de se estabelecer, sempre provisoriamente, este «padrão» é contar-se com as opiniões dos críticos mais sensíveis de cada época. Seriam eles que, transcendendo suas opiniões subjetivas, as mesmas que todos seres humanos exercem de forma idiossincrática e compartilham em torno de sensos comuns, tornariam suas análises fatos objetivos e singulares. Suas críticas criariam padrões sem implicar nenhuma normatização ou preceito regulador, apenas como suportes para que outros pudessem fruir as obras, previamente criticadas e relativizadas frente a outras, com um engajamento e prazer maiores. Com isso permitiriam que se estabelecesse um valor objetivo às obras criticadas, além da pura percepção sensível e subjetiva, extensiva e comum a todos. Esse juízo mais refinado, o senso comum sempre sujeito ao reexame empírico no exercício do gosto diante da obra, a cada nova crítica e em cada novo momento histórico em que esta emergisse, já pareceria validado desde então como algo produtivo, pois, dependendo de sua efetiva qualidade de síntese possível, e beneficiaria outros observadores permitindo que diante do padrão de gosto implícito àquela avaliação fruíssem as obras de arte melhor e mais intensamente (Hume, 2004). Este ensaio de Hume, despretensioso e divertido, antecipa grandemente a reflexão kantiana no que diz respeito ao juízo estético, em que se combinam a percepção sensível e subjetiva das obras e o entendimento que as processa racionalmente. Se Kant opta por uma solução mais radical para lidar com o que chama de o «livre e harmonioso jogo da imaginação e do entendimento», em que define como fundamental a não intencionalidade do produtor e o desinteresse do receptor na validação do sentimento do belo, Hume, sem precisar de um cânone perpétuo, e admitindo a volubilidade do gosto e dos valores estéticos, enfrenta o problema de modo mais simples e direto. Um corpo de especialistas trabalha sistematicamente numa contínua e sempre reexaminada valoração das criações 
estéticas, e esse trabalho, ou essa obra, é importante para elevar a qualidade da fruição artística da humanidade. Estudiosos perguntam-se porque Hume preferiu defender a busca seletiva por críticos muito competentes, em vez de propor um método para o autoaperfeiçoamento estético acessível a todos. De algum modo, esta alternativa aparece esboçada na solução essencialista kantiana, que evita o risco da avaliação ilegítima, fundada em conceitos ou preceitos morais, e busca uma racionalidade possível na imprevisível experiência estética (Kant, 2001). Por certo, mesmo que hoje tenham sido superadas noções cruciais para Kant, como as do belo e a do gênio, sua estética reverbera na contemporânea utopia do espectador emancipado, em que além de se tornar artista o agente receptor também se faz crítico. Sem me desviar a ponto de me perder na complexidade do ensaio de Hume e da crítica do juízo kantiana, mas enfatizando a solução filosófica original e produtiva do filósofo escocês, de um cânone não dogmático e de um padrão de gosto não consensual, cabe colher dele, ainda, algo que colabore nessa nossa reflexão pontual. Destaco assim as virtudes e aptidões que, para Hume, esses ideais críticos criadores de padrão deveriam possuir.

Entre as virtudes imprescindíveis: perfeita serenidade da mente; pensamento concentrado e atenção detida sobre o objeto. Somam-se as capacidades e habilidades da delicadeza de imaginação e de gosto, e uma rápida e precisa percepção, no talento de identificar o ponto de vista da obra e, assim, «preservar sua mente livre de todo preconceito» e «permitir que nada entre em sua consideração a não ser o próprio objeto em questão». A tudo isso, deve somar-se o bom senso de perceber a consistência e uniformidade do todo, observando até que ponto a obra alcançou o fim específico para o que, intui-se, ela foi projetada. Como se vê, é uma perspectiva finalista e ainda funcionalista, como o é a tradição da mimesis realista, e bem distante da programática e necessária não finalidade explícita da estética kantiana, quanto mais da hegemonia do espectador, na contemporânea estética relacional e nas formas performativas de interatividade, que hoje aparecem como meras convenções quase padronizadas no âmbito do espetáculo.

Minha provocação por ora é: enquanto críticos em uma cena contemporânea tão aberta e incomensurável e, ao mesmo tempo, tão domesticada e mercantilizada, cabe a nós cultivar algumas dessas qualidades que a Hume pareciam desejáveis a quem exercesse essa nobre função? Cabe defender um padrão de gosto, ainda que este, no limite, sirva para cada obra, a cada vez que se a defronta? 
As questões que essa possibilidade de pensar grande e amplamente a crítica das artes cênicas e performativas, com todas as implicações de estendê-la a um diálogo com a crítica de arte em geral e com a esfera pública em particular, são muitas. Paira o risco de, ao abrir-se essa caixa de Pandora, acabar-se tendo de discutir tudo antes de se discutir a crítica.

Mas evocar Hume, um ponto de vista estranho ao nosso tempo e decididamente anacrônico, é estratégico. Oferece-nos um novo ângulo cuja aparente e improvável pertinência e, se efetiva, aferível potência abre um atalho para se caminhar diante da imensidão do problema.

Sem o acabamento e a pretensão totalizante da estética kantiana, é uma reflexão filosófica importante sobre a arte. Participa honrosamente numa tradição de comentários estéticos de filósofos, partilhada com os franceses Rousseau e Diderot, seus contemporâneos de século XVIII, e com os românticos alemães do século seguinte, Schopenhauer e Hegel, bem como com Nietzsche. Contemporaneamente é um fato objetivo que filósofos como Adorno, Agamben e Deleuze hegemonizem nos discursos críticos e nos ensaios acadêmicos sobre as artes. É quase como se no caso desses últimos e, principalmente na perspectiva deleuziana, as suas fossem já filosofias não para filósofos, mas para artistas. Filosofias estéticas para uma arte confundida com a vida, ou para pensar uma vida tornada arte. Até por isso, são hoje os nomes dominantes que instauram padrões de gosto ou valor estético, ou fornecem paradigmas que se tornam habituais e se prestam às mais diversas análises. Ao mesmo tempo, a leitura de Deleuze da pintura de Francis Bacon, por exemplo, não se confunde com a da crítica especializada em artes visuais e a estranha. O Bacon que Deleuze pinta é o que revela a sua filosofia, é o que fornece a prova material do seu pensamento e não o que a história da arte oficializou. Literalmente, sua «crítica» é uma criação a partir de Bacon no mesmo sentido que certas telas do pintor irlandês são feitas a partir de uma conversa sua com Velázquez (Deleuze, 1981).

Mas seria o caso, efetivamente, deste filósofo dominante nos estudos estéticos e recorrente nos discursos críticos atuais tornar-se um guia necessário de um padrão de gosto? A despeito da riqueza de suas análises criativas de artistas de vários matizes, parece estranho que um pensamento tão simpático ao indeterminado e ao devir se torne, como se tornou (nove entre dez teses em artes cênicas no Brasil citam Deleuze copiosamente), uma grade necessária a filtrar todas as leituras e a inexoravelmente favorecer um padrão de gosto hegemônico. Me pareceria mais saudável e mais transformador, retomando Hume na sua inocência 
pré-moderna, estimular o amor da crítica pelo objeto confrontado sem viseira que o anteceda. Focar em sua singularidade e concretude e tentar descobrir o que ela teria a dizer, fazer, mostrar por si, induzindo o parto da crítica, digamos, por meios naturais, sem impor cortes artificiais nem o uso de fórceps, ou à base de preconceitos estranhos às obras.

Ao mesmo tempo, o que me parece mais interessante na proposta de Hume, e evocável nesse contexto, é o seu chamado à função social da crítica e o profundo senso de comunidade que a sua defesa do padrão de gosto enseja.

Como diz Paul Guyer no ensaio «The standard of Taste and the "Most Ardent Desire of Society" ", o crítico em Hume não apenas descobre o bom gosto mas é parte dos meios pelos quais uma comunidade de gosto pode ela própria se constituir (Guyer, 2005). Apresentado em meio a uma história do gosto não depende dela, pois seu valor para a arte e a cultura não é o de aquiescer frente ao gosto que detecta vigente - o que só o tornaria um bom guia de investimento no mercado da arte - mas sim o de estabelecer os termos em que novos gostos, quaisquer que fossem, deveriam ser preservados ou superados. Isto quer dizer que o crítico ideal de Hume não é só um cientista do gosto especialmente qualificado, o que seria perfeitamente descartável, mas parte relevante dos meios pelos quais uma comunidade se constitui e reconhece sua própria identidade. A delicada sensibilidade que se lhe exige $o$ aproxima na verdade do artista, o que me permite sugerir que, nesse pequeno grande ensaio de Hume, não só se esquadrinham os termos básicos de uma filosofia da produção e fruição estética modernas, como aparece pioneiramente a ideia do crítico como artista, a ser retomada mais de um século depois por Oscar Wilde.

No diálogo «O Crítico como Artista», de 189o, Gilbert, o personagem que vocaliza Wilde, não só defende o criticismo como uma arte, como percebe o crítico como mais criador do que o artista. Em sua forma mais perfeita, o criticismo é visto como mais criativo que a criação que mira, por ser o exercício mais puro da impressão pessoal e não se referenciar a nenhum padrão externo a si próprio (Wilde, 2008). Ou talvez fizesse mais sentido, já no século XxI, recordar a posição de Rothko quando afirma que a função do artista é similar àquela do filósofo, pelo tipo de generalização que cada um deles faz quando operam suas capacidades de compreensão, o que chama de «qualidade sintética», em contraste com a generalização especializada dos cientistas (Rothko, 2004).

De qualquer modo, estariam os críticos, então, situados entre os filósofos e os artistas? Seriam eles veros criadores de pensamentos, heróis 
da resistência ao menoscabo da beleza e da inteligência? Já não precisamos de tanto glamour. Talvez o principal da lição de Hume, até por ser despretensiosamente pré-romântica e eivada de bom senso, é o de requerer o trabalho diligente e paciente em qualquer das modalidades de exercício crítico, seja o cotidiano diálogo pelos jornais e blogues com o público e artistas, a quente, seja os voos de maior fôlego na produção ensaística ou nos processos criativos de companhias e/ou artistas individuais, mais meditados. Há sempre extremos indesejáveis que hoje podem oscilar entre o voluntarismo das opiniões descabeladas lançadas à rede sem medida ou escrúpulo e o mercenarismo do aconselhamento de consumo que só faz reiterar a distância entre o teatro e a arte e promover a miséria da crítica. Nem tanto ao mar, nem tanto ao céu. Mesmo na academia com seu compromisso com as ciências pode haver assombro e iluminação.

Recentes pesquisas arqueológicas puseram de pernas para o ar certezas de há muito ensinadas e repetidas sobre o teatro grego antigo e exigem reflexões novas e revigorantes. A empiria, um princípio central para Hume, provou que os grandes teatros de pedra cavados em encostas, onde supostamente milhares de cidadãos atenienses assistiam às tragédias de Sófocles e Eurípides, são uma realidade do período do fim do século IV a. C., quando Atenas já estava sob a dominação de Alexandre da Macedônia. Se os cidadãos do século $v$ assistiram às grandes tragédias refletindo por meio de suas tramas o seu próprio apogeu como civilização, como se tornou canônico observar, o devem ter feito em bancos de madeira e em teatros muitos menores do que os que, imaginávamos, tinham ocupado, quase se desfazendo aí o mito da tragédia grega como acontecimento cívico e massivo da democracia ateniense. Uma nova evidência sobre a arte do passado nos obriga a criar novas narrativas, e descobrir novos pontos de vista críticos. Porque o presente é sempre o motor e o destino incontornável no trabalho de separar e juntar, discriminar e embaralhar, remexer e sintetizar.

Isso nos traz de volta ao título desse ensaio, que evoca um paradoxo crucial de nosso tempo, sintetizado na antinomia da expansão e da contração e que pode ser apresentado tanto no âmbito da linguagem, ou da crítica da linguagem, como já se esboçou, ou nos planos social e político dos grandes coletivos humanos e da história presente em que eles se debatem e lutam e migram e se retraem.

Numa perspectiva geográfica e econômica, os processos recentes de migração intensiva de populações vitimadas por guerras e violências semeadas há décadas, principalmente depois da invasão do Iraque, 
e a contrapartida europeia de retração e fechamento a essas levas de refugiados são o trágico emblema desse paradoxo, que tem em contrapartida a imensa carga de esperança e vontade de futuro e a enorme expansão das pulsões de vida e de experiências que o fim das fronteiras da velha e conflagrada Europa chegou a gerar e ainda gera. Talvez, nesse quadro atual, em que os países e suas populações se ensimesmam ameaçados e uma tenebrosa crise se anuncia a partir desse refluxo, também contraste fortemente o otimismo da revolução tecnológica e da expansão ilimitada de possibilidades de conexão e comunicação por ela criadas, com o pessimismo que a desumanização das relações e o isolamento crescente dos indivíduos, rarefeitos diante de suas máquinas autossuficientes, ensejam e deixam entrever.

Do mesmo modo, assim como esse excesso de velocidade e amplitude na circulação de informações e opiniões não resulta necessariamente em mais coesão social, solidariedade e consenso, a expansividade dos territórios e dos procedimentos no campo das artes não implica necessariamente em comunidades artísticas menos refratárias às diferenças essenciais dos seus respectivos meios e especificidades. $\mathrm{E}$ se as artes por um lado se expandem, as sociedades em que elas circulam e se afirmam não lhes acompanham a dilatação e transparência de seus tecidos, estando em processos históricos tensos, sujeitos a contradições insuperáveis e prenhes de violência.

Diante dessas aporias e desses contrastes paradoxais, o papel da crítica de arte se adensa e se politiza, pois o olhar crítico já não pode diferenciar, no diálogo com a comunidade que o acolhe, as dimensões estética e existencial. Arte é vida e a crítica de arte, além da miséria da política, é crítica do homem e do humano.

Como muito bem afirma o crítico de arte brasileiro Luiz Camilo Osorio, em seu ótimo livro sobre a atualidade da estética kantiana, Razões da Crítica:

A universalidade reclamada pelo juiz estético não se impõe por uma certeza, mas é requisitada por sua gratuidade e singularidade. Essa pretensão universal é que faz com que o juízo estético abra um espaço sempre negociável de sentido, de novos sentidos que se querem comuns. A necessidade de julgar se impõe pela força singular do fenômeno poético, que não é determinável por uma expectativa prévia ou por um saber constituído. Convocados a ajuizar, a decidir sobre os sentidos em causa, nos colocamos abertos aos outros, dispostos a expor nossos pontos de vista 
que são uma entrega para a diferença a ser conquistada e/ou enfrentada, abrindo um lugar em que a multiplicidade, o dissenso e a liberdade nos façam conscientes de nossa pertença no mundo. (Osorio, 2005: 67)

É evidente que além da qualquer questão do universo da estética, ou do teatro como campo e como problema, estamos em um momento histórico crucial que demanda, além de dossiês como esse, uma ação e inteligência coletivas, em escala planetária, que nos impulsione além do que vai surgindo como uma inevitável catástrofe social e econômica, e em que a política, esvaziada de toda potência, torna-se uma coadjuvante sem relevância.

A despeito da gravidade desse tempo, afinal nem tão menor da que colheu a primeira metade do século xx e suas duas guerras mundiais horrendas, e só contrastada com as esperançosas décadas de prosperidade e paz dos últimos setenta anos, a vida e a arte continuam nos desafiando a decifrá-las e produzi-las e criticá-las. Como críticos de arte ou de teatro, como o prefiram perfilar-se, teremos sempre algo próprio a fazer e a pensar, a urdir ou a criar, um trabalho que, mistificado ou rebaixado, persistirá como necessário e inexorável à condição humana.

\section{REFERÊNCIAS BIBLIOGRÁFICAS}

CRAIG, Edward Gordon (2017), Rumo a Um Novo Teatro \& Cena, São Paulo, Perspectiva.

DELEUZE, Gilles (1981), Francis Bacon: Logique de la sensation, Paris, Éditions de la Différence.

GUYER, Paul (2005), «The standard of Taste and the "Most Ardent Desire of Society" » in Values of Beauty, Cambridge, Cambridge University Press, pp. 37-74.

HAlliwell, Stephen (2002), The Aesthetic of Mimesis: Ancient Texts and Modern Problems, Princeton e Oxford, Princeton University Press.

Hume, David (2004), «Do Padrão de Gosto», in Ensaios Morais, Políticos \& Literários, Rio de Janeiro, Liberty Fund e Topbooks, pp. 367-96.

KANT, Immanuel (2001), Critique of the Power of Judgment, Cambridge, Cambridge University Press.

os ORIo, Luiz Camillo (2005), Razões da Crítica, Rio de Janeiro, Zahar.

RAMOs, Luiz Fernando (2015), Mimesis Performativa: A Margem de Invenção Possível, São Paulo, Annablume.

- (2017), «A relação entre atores e screens no teatro de Gordon Craig: um legado à contemporaneidade», in Discursos do Corpo na Artes vol. II, Santa Maria, editora UFSM, pp. 11-42.

Rотнко, Mark (2004), The Artist's Reality - Philosophies of Art, New Haven e Londres, Yale University Press.

WILDE, Oscar (2008), «The Critic as Artist», in Complete Works of Oscar Wilde - Stories, Plays, Poems and Essays, Londres e Nova Iorque, Harper Perennial, pp. 1009-1059. 


\section{LUIZ FERNANDO RAMOS}

Luiz Fernando Ramos é professor do Departamento de Artes Cénicas da Universidade de São Paulo desde 1998, leccionando as disciplinas de Crítica, História e Teoria do Teatro. Em 2012 tornou-se professor associado. É pesquisador do CNPq - Conselho Nacional de Desenvolvimento Científico e Tecnológico desde 2006 e coordena o GIDE - Grupo de Investigação do Desempenho Espectacular. É encenador, dramaturgo e documentarista. É autor de Mimesis Performativa: A Margem de Invenção Possível (Annablume, 2015). Foi crítico de teatro da Folha de S. Paulo entre 2008 e 2013. É editor responsável da revista Sala Preta do programa de pós-graduação em Artes Cénicas da Universidade de São Paulo. 